\title{
Actualización:
}

\section{Estudios de laboratorio - Parte II}

\author{
Laboratory tests - Part two
}

Gabriel Ruiz *

Palabras clave: estudios de laboratorio, alfa fetoproteína, péptido natriurético, perfil óseo, CA 125, troponinas cardiacas, antígeno carcinoembrionario (CEA), índice de filtración glomerular, $\mathrm{HbA} 1 \mathrm{c}$, función hepática, antígeno prostático especifico (PSA). Key words: laboratory tests, alfa fetoprotein, natriuretic peptide, bone profile, CA 125, cardiac troponins, carcinoembrionic antigen (CEA), glomerular filtration rate, HbA1c, hepatic function, and prostatic specific antigen

Ruiz G. A. Estudios de laboratorio - Parte II. Evid Act Pract Ambul. Vol 14(1):22-23. Ene-Mar 2011.

\section{Alfa Fetoproteína}

Es una glicoproteína serica fetal, indetectable al momento del nacimiento. La principal causa de su elevación son el carcinoma hepatocelular, y el cáncer testicular de células germinales tumorales no seminomatosas, existiendo otras causas menos frecuentes como el cáncer gástrico, y otras no neoplásicas como la cirrosis. En el embarazo su elevación puede asociarse a anencefalia, espina bífida, defectos de la pared abdominal (onfalocele), trisomía 18 y síndrome de Down. El valor de corte es de $1,000 \mathrm{ng} / \mathrm{ml}(<10 \mathrm{kU} / \mathrm{L})$ y su uso no està indicado para rastreo/tamizaje en la población general.

En el embarazo se puede usar en forma combinada junto a la ecografía y eventualmente otros tests para estratificar el riesgo de síndrome de Down $n^{1,2,3,4}$

\section{Péptido natriurético}

El corazón produce especialmente dos tipos de péptidos (el péptido natriurético atrial, secretado principalmente por la dilatación de la aurícula, y el péptido natriurético cerebral, secretado casi exclusivamente por el ventrículo cardíaco ante elevaciones de la presión diastólica y el volumen).

Algunos expertos recomiendan utilizarlos para valorar la severidad y controlar el tratamiento de la insuficiencia cardiaca (IC). Por ejemplo, valores normales de péptido natriurético cerebral virtualmente descartan una disfunción ventricular izquierda, mientras que valores elevados son sugestivos de IC y de la necesidad de realizar otras pruebas diagnósticas como ecocardiograma ${ }^{2}$. De todos modos, el rol de estos marcadores en la IC está todavía bajo estudio y discusión por lo que no se recomienda actualmente utilizarlos en forma rutinaria ${ }^{5}$.

\section{Marcadores del metabolismo fosfocálcico}

La valoración de algunos marcadores del metabolismo fosfocálcico es sugerida ante la sospecha de posibles alteraciones del metabolismo óseo y/o renales, no recomendándose como tamizaje. Suele incluir la valoración de la calcemia, la fosfatasa alcalina y los fosfatos. Estos valores pueden estar aumentados en presencia de hiperparatiroidismo primario o secundario, alteraciones osteolíticas, sarcoidosis y exceso de vitamina $D$; mientras que los mismos disminuyen ante deficiencias de vitamina $D$ o insuficiencia renal.
Existen otros marcadores, generalmente resorte del especialista, como los de formación òsea (osteocalcina, propéptidos de colágeno tipo I carboxil Terminal, propéptidos de colágeno tipo I amino terminal) y los de resorción ósea (en orina, hidroxiprolina, piridinolinas totales y libres, deoxipiridinolinas totales y libres, $\mathrm{N}$-telopéptidos de los enlaces de colágeno y C-telopéptidos de los enlaces de colágeno; y en suero, los enlaces unidos a C-telopéptidos de colágeno tipo I, Fosfatasa ácida resistente a tartrato).

Son valores de referencia de fosfatasa alcalina, 40 a $129 \mathrm{U} / \mathrm{L}$ en varones adultos y 35 a $104 \mathrm{U} / \mathrm{L}$ en mujeres adultas; 2,15 a $2,55 \mathrm{mmol} / \mathrm{L}$ el calcio y 0,87 a $1,45 \mathrm{mmol} / \mathrm{L}$ el fosfato.

Perfiles de algunas patologías

Osteomalacia: hipofosfatemia, hipocalcemia, fosfatasa alcalina aumentada.

Enfermedad de Paget: calcio normal, fosfatasa alcalina aumentada.

Osteoporosis: calcemia normal y fosfatasa alcalina normal.

\section{CA 125}

Es una glicoproteína que se expresa en el epitelio celómico durante el desarrollo fetal. Se utiliza principalmente para el seguimiento de los pacientes con cánceres epiteliales de ovario, pudiendo tambien estar aumentado en otros procesos (adenocarcinomas de cualquier origen, cirrosis, endometriosis, etc.). Presenta una baja sensibilidad por lo cual NO se justifica su uso para $\mathrm{cribado}^{5}$, siendo su rango de referencia 0 a 35 $\mathrm{KU} / \mathrm{L}$.

\section{Troponina}

Es una proteína globular de gran peso molecular, presente en músculo estriado y cardiaco. Las troponinas $\mathrm{T}$ y troponinas I son específicas del músculo cardiaco. Aumentan ante daños miocárdicos, aunque existen falsos positivos (accidente cerebrovascular, embolia pulmonar, ejercicio extenuante, insuficiencia renal). Existe amplio consenso de que su sensibilidad oscila entre 90 y $100 \%$ a las 12 horas de producido el evento, mientras que algunos estudios informan una sensibilidad de $90 \%$ y una especificidad del $95 \%$ a las ocho horas de iniciado el dolor de pecho ${ }^{6}$.

Si bien se trata de un estudio fiable ante un paciente con dolor

* Médico Generalista. Albardón. San Juán. garuizgio@ yahoo.com.ar 
precordial, no permite por si sólo realizar diagnósticos. En este sentido, recordamos que en el abordaje de los pacientes con síndrome coronario, debe ser interpretado en el contexto de la semiología clínica y, eventualmente otros estudios complementarios.

\section{Antígeno carcino-embrionario}

El antígeno carciono embrionario (CEA) es una glicoproteína que se encuentra en las mucosas normales y en los adenocarcinomas, especialmente en el colorrectal, siendo sus valores normales menores a $5 \mathrm{mg} / \mathrm{L}$, pudiendo tambien elevarse en pacientes con cirrosis, enfisema, ictericia obstructiva y colitis ulcerosa.

Se utiliza para la estratificación de cáncer colorrectal, no justificándose para el rastreo de esta patología. Tendría cierta utilidad pronóstica en el contexto de la evaluación prequirúrgica de estos pacientes, asociándose valores altos a peor pronóstico. Por otro lado, si la resección quirúrgica fue completa los valores de CEA suelen retornar a valores normales, no disminuyendo ante resecciones incompletas.

\section{Tasa de filtración glomerular}

La tasa de filtración se puede estimar de diferentes maneras. S bien el patrón de oro es el índice de depuración de inulina, no suele utilizarse debido a que se trata de un método engorroso, usandose cuando se necesita gran precisión, la depuración o "clearence" de creatinina de 24 horas, que implica una extracción de sangre y la recolección de orina de 24 horas. Además, puede estimarse a través de un cálculo que se basa en la concetración de creatinina plasmática, la edad y el sexo del paciente.

En adultos sanos se consideran valores normales 100 $\mathrm{mL} / \mathrm{min} / 1,73 \mathrm{~m}^{2}$, pudiendo estar aumentada en los inicios de la nefropatía diabética $(120 \mathrm{~mL} / \mathrm{min})$ y reduciéndose a 60 a 90 $\mathrm{mL} / \mathrm{min}$ en estados de deshidratación (en forma aguda) o en pacientes con diabetes, hipertensión, ateroesclerosis, obstrucción de la vejiga, hiperplasia de próstata, litiasis, insuficiencia renal (en forma crónica).

Puede estar algo reducida en un $30 \%$ de las personas sanas, por lo que ante un valor alterado sin causa aparente es razonable repetirla a los seis meses. De ser menor a $60 \mathrm{ml} / \mathrm{min}$ indica falla renal, lo que hace considererar la derivación a nefrología ${ }^{7}$.

Vale destacar que la mayoría de las guías de práctica clínica recomienda valorar la creatininemia en pacientes con diabetes, hipertensión y dislipidemias.

\section{Hemoglobina glicosilada}

La hemoglobina glicosilada (Hba1c) es un marcador serológico que cuenta con amplia evidencia para predecir la incidencia de complicaciones de largo plazo (especialmente microvasculares) relacionadas con diabetes (especialmente en pacientes con diabetes tipo 1). Por ejemplo en el ensayo clínico $D_{C C T^{8}} y$ luego de 11 años de seguimiento, los pacientes sometidos a tratamiento insulínico intensificado y comparados con los asignados al tratamiento usual de aquel momento histórico (década de los ochenta y noventa del siglo XX) registraron un promedio de $7,4 \%$ vs. $9,1 \%$, lo que se asoció a una contundente menor incidencia de nefropatía y de retinopatía diabética (1\% anual en quienes tenían $\mathrm{HbA} 1 \mathrm{c}$ cercana a $5,5 \%$ vs. $9,5 \%$ en quientes tenían una $\mathrm{HbA} 1 \mathrm{c}$ cercana a 10,5\%).

$\mathrm{Si}$ bien existen algunos argumentos en su contra -especialmente en países en desarrollo y debido a su alto costo y su no tan alta disponibilidad-, se trata de un estudio fiable para el seguimiento y la toma de decisiones en pacientes con diabetes, siendo hoy en día el principal marcador de corto plazo del control de la diabetes.

Se debe tener en cuenta que las alteraciones de los glóbulos rojos pueden perturban sus resultados. Actualmente la Asociación de Diabetes Americana la considera como alternativa a la glucemia para el diagnostico de diabetes ${ }^{9}$.

\section{Antígeno prostático específico (APE o PSA en inglés)}

Es una glucoproteína producida por la próstata, casi exclusiva de las células epiteliales de la misma. Podríamos decir que es órgano específica, pero no cáncer especifica, porque puede estar aumentada también en la Hiperplasia Prostática Benigna y las prostatitis. El valor predictivo positivo para cáncer es de 25 a $35 \%$ para los niveles de 4 a $10 \mathrm{ng} / \mathrm{mL}$ y de 50 a $80 \%$, para los valores que superan los $10 \mathrm{ng} / \mathrm{mL}$.

Aunque todavía no existe evidencia que avale el rastreo de cáncer prostático $0^{10,11,12,13}$, hay algunos consensos que recomiendan solicitarlo en forma rutinaria en los mayores de 50 años, mientras que otros recomiendan no hacerlo. Entre sus principales aplicaciones se destaca que en combinación con tacto rectal puede ayudar a diagnosticar cáncer de próstata. Son rangos normales de valores de PSA por edad: 0 a 2,5/mL entre los 40 y los 49 años; 0 a 3,5/mL entre los 50 y los 59; 0 a $4,5 / \mathrm{mL}$ entre los 60 y los 69 ; y 0 a $6,5 / \mathrm{mL}$ entre los 70 y los 79 .

\section{Referencias}

1. Kooper A y col. Fetal anomaly scan potentially will replaceroutine AFAFP assays for the detection of neural tube defects. Prenat Diagn 2007;27:29-33. available from: www.dare.ubn.kun.nl/bitstream/2066/74947/1/74947.pdf

2. Eldad S y col. Diagnosis of hepatocellular carcinoma. HPB (Oxford). 2005; 7(1): 26-34. avaliable from: http://www.ncbi.nlm.nih.gov/pmc/articles/PMC2023919/ 2. Eldad S y col. Diagnosis of hepatocellular carcinoma. HPB (Oxford). 2005; 7(1): 26-34. avaliable from: http://www.ncbi.nlm.nih.gov/pmc/articles/PMC2023919/
3. Johnson P. The role of serum alpha-fetoprotein estimation in the diagnosis and management of hepatocellular carcinoma. Clin Liver Dis. 2001 Feb;5(1):145-59. [abstract]

4. Sánchez-Muñoz A y col. Limitaciones al uso de los marcadores tumorales séricos en la práctica Oncológica Notas Clínicas Oncología, $2005 ; 28$ (9):443-447 avaliable from: www.scielo.isciii.es/pdf/onco/v28n9/04.pdf

5. Cunningham S y col. Guidelines on the use of biochemical cardiac markers and risk factors. Association of clinical biochemists in Ireland. Published by the ACBI in November 2002. 6. Ebell $\mathrm{M}$ y col. A systematic review of troponin $\mathrm{T}$ and I for diagnosing acute myocardial infarction. J Fam Pract. 2000 Jun;49(6):550-6.avaliable in: http://www.ncbi.nlm.nih.gov/pubmed/10923557

7. Northern Ireland Guidelines for management of chronic kidney disease Developed by GAIN and the Northern Ireland Nephrology Forum February 2010 avaliable from: http://www.gain7. Northern Ireland Guidelines for management of chronic kidney disease Developed by GAIN and the Northern Ireland Nephrology Forum February 2010 avaliable from: http://www.gainni.org/Library/Guidelines/index.asp

8. The Diabetes Control and Complications Trial Research Group. The effect of intensive treatment of diabetes on the development and progression of long-term complications in insulin-dependent diabetes mellitus. N Engl J Med 1993 Sep 30;329(14):977-86.

9. Chamnan $\mathrm{P}$ y col. Incidence of type 2 diabetes using proposed HbA1c diagnostic criteria in the EPIC-Norfolk cohort: implications for preventive strategies. Diabetes Care. 2010 Jul 9. http://www.ncbi.nlm.nih.gov/pubmed/20622160

10. Heidenreich M y col. Directrices sobre Cáncer de Próstata. A. Asociación Europea de Urología 2010 disponible en: http://www.uroweb.org/?id=218\&gid=3

11. llic D y col. Screening for prostate cancer: a Cochrane systematic review. Cancer Causes Control. 2007 Apr;18(3):279-85. Epub 2007 Jan 6. http://www.ncbi.nlm.nih.gov/pubmed/19297566 12. Djulbegovic M, Screening for prostate cancer: systematic review and meta-analysis of randomised controlled trials. BMJ. 2010 Sep 14;341:c4543. doi: 10.1136/bmj.c4543.

12. Djulbegovic M, Screening for prostate cancer: systematic review and meta-analysis of randomised controlled trials. BMJ. 2010 Sep 14;341:c4543. doi: 10.1136/bmj.c4543.
13. Ciapponi A. Nueva Evidencia sobre el rastreo de cáncer prostático: ¿Nuevas recomendaciones? Evid. Act. Pract. Ambul. 13(4).122-124. Oct-Dic. 2010. Disponible en URL: http://www.evidencia.org/hitalba-pagina-articulo.php?cod_producto=2774\&origen=2 